\title{
WOMEN IN CANCER THEMATIC REVIEW Circadian rhythmicity and the influence of 'clock' genes on prostate cancer
}

\author{
Zsofia Kiss $^{1,2}$ and Paramita M Ghosh1,2,3
}

IVA Northern California Health Care System, Mather, California, USA

2Department of Urology, University of California at Davis, Sacramento, California, USA

${ }^{3}$ Department of Biochemistry and Molecular Medicine, University of California at Davis, Sacramento,

California, USA

Correspondence

should be addressed

to P M Ghosh

Email

paghosh@ucdavis.edu

\begin{abstract}
The androgen receptor (AR) plays a key role in the development and progression of prostate cancer (CaP). Since the mid-1990s, reports in the literature pointed out higher incidences of CaP in some select groups, such as airline pilots and night shift workers in comparison with those working regular hours. The common finding in these 'high-risk' groups was that they all experienced a deregulation of the body's internal circadian rhythm. Here, we discuss how the circadian rhythm affects androgen levels and modulates CaP development and progression. Circadian rhythmicity of androgen production is lost in CaP patients, with the clock genes Per1 and Per2 decreasing, and Bmal1 increasing, in these individuals. Periodic expression of the clock genes was restored upon administration of the neurohormone melatonin, thereby suppressing CaP progression. Activation of the melatonin receptors and the AR antagonized each other, and therefore the tumour-suppressive effects of melatonin and the clock genes were most clearly observed in the absence of androgens, that is, in conjunction with androgen deprivation therapy (ADT). In addition, a large-scale study found that high-dose radiation was more effective in CaP patients when it was delivered before 17:00 h, compared with those delivered after 17:00 h, suggesting that the therapy was more effective when delivered in synchrony with the patient's circadian clock. As CaP patients are shown to become easily resistant to new therapies, perhaps circadian delivery of these therapeutic agents or delivery in conjunction with melatonin and its novel analogs should be tested to see if they prevent this resistance.
\end{abstract}

$\begin{aligned} & \text { Key Words } \\ & \text { - circadian clock } \\ & \text { - androgen receptor } \\ & \text { - melatonin } \\ & \text { - per1 } \\ & \text { - bmal1 }\end{aligned}$

Endocrine-Related Cancer (2016) 23, T123-T134

\section{Introduction}

The prostate is an androgen-dependent organ that relies on male hormones (androgens) for growth and maintenance. In disease states, androgens can stimulate oncogenes that promote cellular proliferation, thus increasing the chances of DNA copy errors. Rodent studies showed that excessive androgen production can induce prostate cancer (CaP) (Brown et al. 1979) and this was later supported by human studies that explored long-term exposure to high levels of androgens (Gann et al. 1996). The androgen receptor (AR) is a member of the nuclear

This paper is part of a special section on Celebrating Women in Cancer Research. The Guest Editors for this section were Charis Eng and Deborah Marsh. 
steroid hormone receptor family that also includes the progesterone receptor and the oestrogen receptor (ER). The AR is responsible for mediating the effects of androgens, which are synthesized primarily by the testes and the adrenal cortex, but also other organs such as skin and ovaries. Androgens play an important role in the development and maintenance of the male reproductive tissues. The AR, in its inactive state, is located in the cytoplasm complexed with other proteins such as the heat shock proteins. It is activated by binding to androgens that cause the AR to transmigrate to the nucleus, where it functions as a transcription factor. The main androgens in humans are testosterone and its more active metabolite, 5-alpha-dihydrotestosterone (DHT), although other androgens such as dehydroepiandrosterone (DHEA), androstenedione, androstenediol and androsterone are also produced. Upon binding to androgens, the AR is freed from its protein complex and is allowed to move to the nucleus, binding target genes through their androgen response elements located in the promoter or enhancer regions. Many of the genes targeted by the AR are involved in the growth and survival of prostate cells; therefore, dysregulation of AR activity is strongly implicated in CaP development and progression.

Primary CaP is mostly treated with either prostatectomy or with radiation therapy, although watchful waiting is a common option. Approximately $30-40 \%$ of those thus treated will experience a recurrence and will be administered androgen deprivation therapy (ADT), which consists of leutenizing hormone-releasing hormone (LHRH) agonists or antagonists, or orchiectomy, to decrease the levels of circulating androgens. ADT is initially effective in $>95 \%$ of patients, but many initial responders develop resistance to ADT and will eventually develop castration-resistant CaP (CRPC). The majority of castration-resistant tumours still express AR, and androgen-regulated genes such as prostate-specific antigen (PSA), indicating that the AR pathway is still active (Denmeade et al. 2003). CRPC patients will be further treated with chemotherapy, immunotherapy, radiotherapy or the use of androgen-signalling inhibitors: the AR inhibitor enzalutamide or the CYP17 inhibitor abiraterone acetate. However, the duration of efficacy of the inhibitors is short and eventually, most patients will develop resistance to these treatments as well.

A series of publications pointed to a pattern of CaP development in unique sets of conditions. A 1996 study in a cohort of 2740 Air Canada pilots showed that standardized incidence ratio (SIR) for $\mathrm{CaP}$ was significantly increased among male pilots $(\mathrm{SIR}=1.87$, 90\% confidence interval (CI) 1.38-2.49) compared with the general population, although there was an overall decrease in cancer-related mortality for all sites of cancer (Band et al. 1996). Following this, in 2003, it was reported that a cohort of 10,051 male airline pilots from Nordic countries (Denmark, Finland, Iceland, Norway and Sweden) experienced an increase in the relative risk of CaP with increasing number of flight hours in long-distance aircrafts $(P=0.01)$ (Pukkala et al. 2003).

In addition, continuing with this pattern, a 2006 study from Japan reported that among 14,052 working men in Japan, compared with day workers, rotating-shift workers were significantly at risk for CaP (relative risk=3.0, 95\% CI: 1.2-7.7) (Kubo et al. 2006). This was borne out by a meta-analysis of 2,459,845 individuals from eight published studies which showed that night shift work was associated with a significantly increased risk of CaP (Rao et al. 2015). The association between night shift work and $\mathrm{CaP}$ risk was particularly strong for tumours with worse prognosis (Papantoniou et al. 2015a).

Based on the reports outlined in the last two paragraphs, a 2006 commentary hypothesized that 'both altered-lighted environments and genetic variations in genes responsible for maintaining circadian rhythms may result in deregulation of clock-associated biological processes, such as androgen expression, and consequently influence an individual's risk of prostate cancer' (Zhu et al. 2006). In support of a role for altered light environments in $\mathrm{CaP}$, a study linking a cohort of 17,557 persons with visual impairment demonstrated decreased incidence of CaP by degree of visual impairment (Pukkala et al. 2006). These reports supported the validity of the chronodisruption hypothesis and indicated a role for the circadian rhythm in the development of $\mathrm{CaP}$.

\section{What is the circadian rhythm?}

Circadian rhythms reflect daily oscillations in biological processes regulated by an internal timing system; for example, the sleep/wake cycles (Fu \& Lee 2003). Circadian rhythm has a very important adaptive significance that greatly influences the behaviour and physiology of all living organisms from prokaryotes to humans. Other functions in the human body that are influenced by the circadian rhythms include thermoregulation, arterial pressure in systemic circulation, endocrine functions, the digestive system and immune response (Reppert \& Weaver 2002). Disruption of circadian rhythms has been

Published by Bioscientifica Ltc 


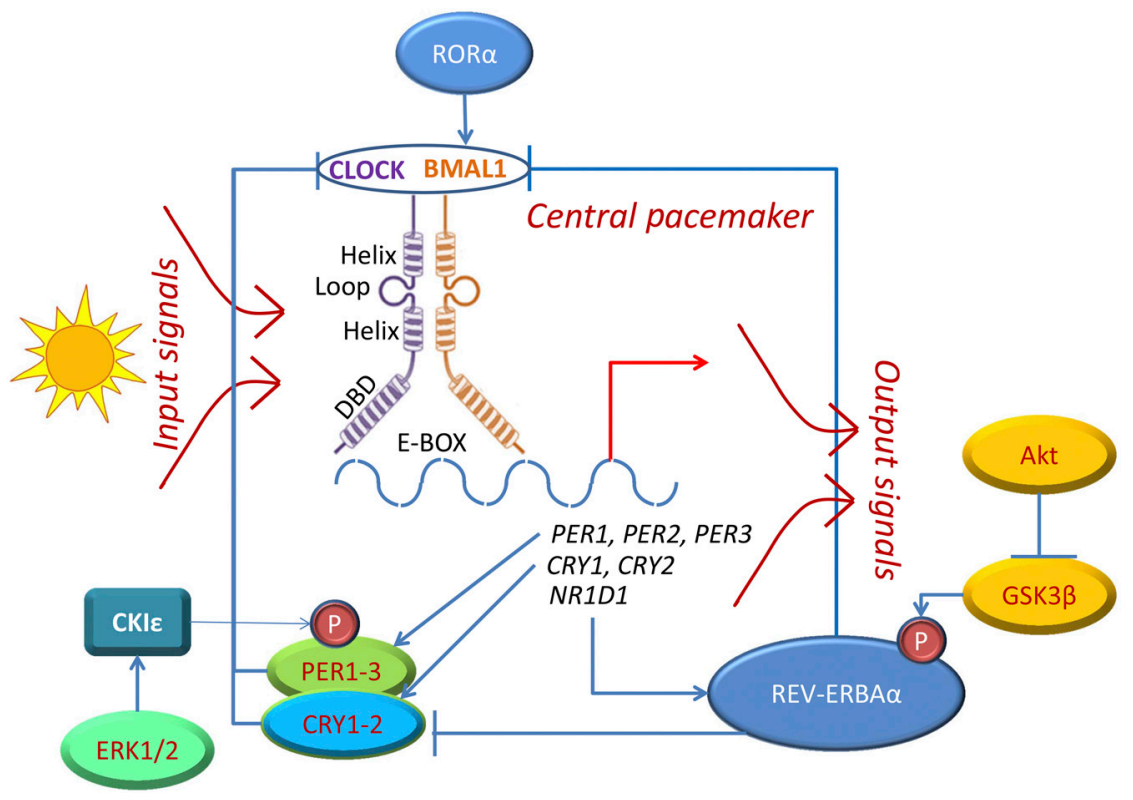

Figure 1

Relationship between the various clock genes. Input signals such as sunlight activate the 8 known core clock genes: period (Per1-Per3), casein kinase $I_{\varepsilon}(\mathrm{CKI} \mid \varepsilon)$, Clock/NPAS2, Bmal1/ARNTL and cryptochrome (Cry1-2). Clock and Bmal1 are two basic helix-loop-helix (bHLH) transcription factors (each containing a bHLH region and a DNA-binding domain - DBD), which bind the E-box sequence (CACGTG) in the promoter of target genes as a heterodimer. Target genes include Per, Cry and NR1D1, which produces an orphan nuclear receptor protein REV-ERBA $\alpha$. When REV-ERBA $\alpha$ is phosphorylated by GSK3 $\beta$, a downstream target of Akt, it transcriptionally represses target genes such as Bmal1 and Cry. In this way, REV-ERBA $\alpha$ balances against the effects of another orphan nuclear receptor $\operatorname{ROR} \alpha$, which transcriptionally upregulates Bmal1. Similarly, Per 1 is regulated by phosphorylation by $\mathrm{CKI} \varepsilon$, which is itself regulated by ERK kinases. Activated Per dimerizes with Cry to form a complex that disrupt the Clock-Bmal1 complex and prevent transcription. $\mathrm{P}$ denotes protein phosphorylation. linked to various human ailments including insomnia, jet lag, stomach ailments, coronary heart attacks, depression and cancer (Reppert \& Weaver 2002).

In mammals, the circadian system is made of three parts: the input pathways, the central pacemaker and the output pathways (Fig. 1). Environmental signals, such as external light, are transmitted via the input pathways to the central endogenous rhythm of the body, the central pacemaker, which transmits neural and hormonal signals to peripheral circadian systems throughout the body (output pathways) (Liu et al. 1997). The central pacemaker resides in the suprachiasmatic nuclei (SCN) of the anterior hypothalamus, which is made up of a number of single-cell circadian oscillators. In a normal individual, the singlecell oscillators are synchronized and generate coordinated circadian outputs (Welsh et al. 1995). However, in disease states, this cycle is disordered and leads to disruption of various functions of the related organs.

Circadian rhythms of the central pacemaker are generated by 8 known clock genes: period (Per1-Per3), casein kinase Ic $(C K I \varepsilon)$, Clock, Bmal1, and cryptochrome (Cry1-2) (Fu \& Lee 2003). Proteins encoded by these genes form a molecular feedback loop that regulates the circadian rhythm (Ko \& Takahashi 2006). Clock and Bmal1 are two basic helix-loop-helix (bHLH) transcription co-activators, which positively regulate the circadian cycle by forming a heterodimer that bind E-box sequences (typically CACGTG) in the promoter of target genes such as Per and Cry (Fig. 1). At the protein level, intracellular expression of Clock remain more or less constant throughout the 24-h period, whereas Bmal1 levels are upregulated at the beginning of the day and fall off as night approaches. At high levels of Bmal1, it forms a heterodimer with Clock, which binds to E-box sequences in the promoters of the Cry, Per and NR1D1 genes to activate transcription at the beginning of a circadian day. NR1D1 encodes the protein Rev-ErbA $\alpha$, which is an orphan nuclear receptor that acts as a transcriptional repressor and participates in the circadian regulation of organs like the brain, liver, skeletal muscle and adipose tissue. It is known to suppress transcription of Bmal1 and the Cry genes. Rev-ErbA $\alpha$ is phosphorylated on the amino terminus by glycogen synthase kinase (GSK $3 \beta$ ), which contributes to its protein stability. Bmal1 is coordinated by opposing effects of RevErbA $\alpha$ and the RAR-related orphan receptor ROR $\alpha$, likely to fine-tune its effect on the circadian rhythm (Fig. 1).

Per1 (rigui) is rhythmically transcribed in the SCN, with a period of approximately $24 \mathrm{~h}$. It is also expressed in other organs, including the prostate. This rhythm is sustained in constant darkness, and with changing light cycles, which likely explains why the circadian rhythm is maintained even in humans with partial or complete visual impairment (Pukkala et al. 2006). The three Per genes encode proteins that contain PER-ARNT-SIM (PAS)- and PAC-domains (Fu \& Lee 2003) (Fig. 2). All three contain a CKIc-binding domain that allows interaction with this kinase and subsequent phosphorylation, and several nuclear localization and export sequences that allow the complex to enter and exit the nucleus as needed (Sun et al. 1997, Tei et al. 1997). Per2 has a similar 


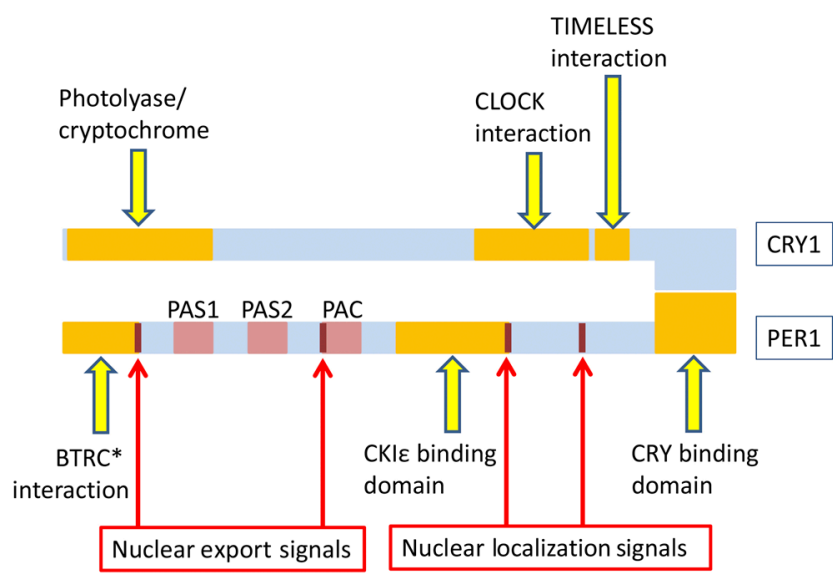

*Beta-Transducin Repeat Containing E3 ubiquitin protein ligase

\section{Figure 2}

General structure of core clock genes Per and Cry. The three Per genes encode proteins that contain the PER-ARNT-SIM (PAS) and the related PAC motifs and form oligomers with the Cry proteins to form functional DNA-binding complexes. Per1 contains a BTRC interaction domain at the $\mathrm{N}$ terminal end. In addition, Per proteins also contain a phosphorylation domain where casein kinase 1 binds and phosphorylates these proteins. The very $\mathrm{C}$ terminus contains a specific domain that allows oligomerization with the Cry proteins. In addition, Per2 contains a PPAR gamma-binding site between the CKIع- and CRY-binding sites that is not seen in Per1 or Per3. Per2 also has a stabilization domain upstream of the PAS motifs not seen in other Per proteins. All Per proteins, however, express nuclear localization and export sequences that allows them to enter and leave the nucleus as needed. The structure of the Cry proteins is much less complex. Both Cry1 and Cry2 contain a cryptochrome (flavoproteins that are sensitive to blue light) interaction domain, as well as a domain that allow them to interact with and inhibit the CLOCK/BMAL1 dimers. In addition, Cry1 also contain a domain that allows interaction with TIMELESS (which negatively regulates CLOCK/BMAL-1 interactions), but this domain is not found in Cry2. (Based on http://www.uniprot.org/.)

function, but in addition, it was shown that Per2 contains glucocorticoid response elements and can interact with PPAR $\gamma$ (So et al. 2009). Cry1 and Cry2 belong to a class of flavoproteins that in plants and insects induce sensitivity to blue light (Hsu et al. 1996). In mammals, they can also act in a light-independent manner as inhibitors of ClockBmal1 components of the circadian clock (Griffin et al. 1999) (Fig. 2).

Per and Cry proteins form oligomers with each other in the cytoplasm, and the oligomeric structure likely stabilizes the complex. In particular, Per2, but not the other Per proteins, contain a stabilization sequence that may allow the stabilization of an oligomeric complex. As the day progresses, the oligomer complex translocate from the cytoplasm, where they are formed, to the nucleus. As night falls, the Per/Cry oligomer interfere with Clock/Bmal1 activity, thereby preventing further accumulation of the components of the oligomer.
Any Per protein accumulated in the cytoplasm is phosphorylated by $\mathrm{CKI} \varepsilon$, an event that leads to a conformational change that masks the proteins stabilization sequence in Per2. This makes the protein complex unstable and it is degraded by ubiquitylation likely by recruitment of the BTRC E3 ubiquitin ligases to the N-terminal region of PER proteins. Interaction with TIMELESS leads to disruption of the Clock/Bmal1-associated transcriptional complex and results in the inhibition of Cry, Per and Rev-Erb $\alpha$ transcription, and de-repression of Bmal1 transcription (Reppert \& Weaver 2001, 2002). The interacting positive and negative feedback loops of circadian genes ensure low levels of Per and Cry, and a high level of Bmal1 at the beginning of a new circadian day (Fig. 3).

\section{Regulation of the circadian clock by melatonin}

The pineal gland in the human brain (so-called because it resembles a pine cone) is best known as a producer of the hormone melatonin, an indoleamine neurohormone derived from the neurotransmitter serotonin, which affects the modulation of sleep patterns in the circadian rhythm. Many of melatonin's biological effects are produced by the interactions of melatonin with its two receptors MT1 and MT2 (Boutin et al. 2005). Melatonin is a powerful antioxidant, and this function may be important in its interaction with the circadian rhythm. Serum melatonin levels are usually elevated nocturnally (80-120 pg/mL) compared with its expression during the day $(2-20 \mathrm{pg} / \mathrm{mL})$, MT1 and MT2 are G-protein coupled receptors (GPCR), which upon activation by melatonin binding, mediate the repression of ROR $\alpha$ transcriptional activity, and hence blocks the expression of the clock gene BMAL1 (Hill et al. 2009) (Fig. 3). During the day, as melatonin levels are degraded, BMAL1 levels increase and resume binding to clock. Studies indicate improved sleep when melatonin is taken at the appropriate time for jet lag and shift work.

The U.S. Dietary Supplement Health and Education Act of 1994 allow synthetic melatonin to be sold as a dietary supplement; there have not been any reported cases of proven toxicity or overdose by melatonin; in fact, melatonin was found to prevent the cytotoxic effects of other drugs (Asghari et al. 2016, Esteban-Zubero et al. 2016), including chemotherapeutic drugs (Demir et al. 2015). Clinical studies indicate a role for melatonin as an adjuvant therapy for sleep disorders of circadian aetiology (jet lag, delayed sleep phase syndrome, sleep deterioration
(C) 2016 Society for Endocrinology Printed in Great Britain
Published by Bioscientifica Ltd 


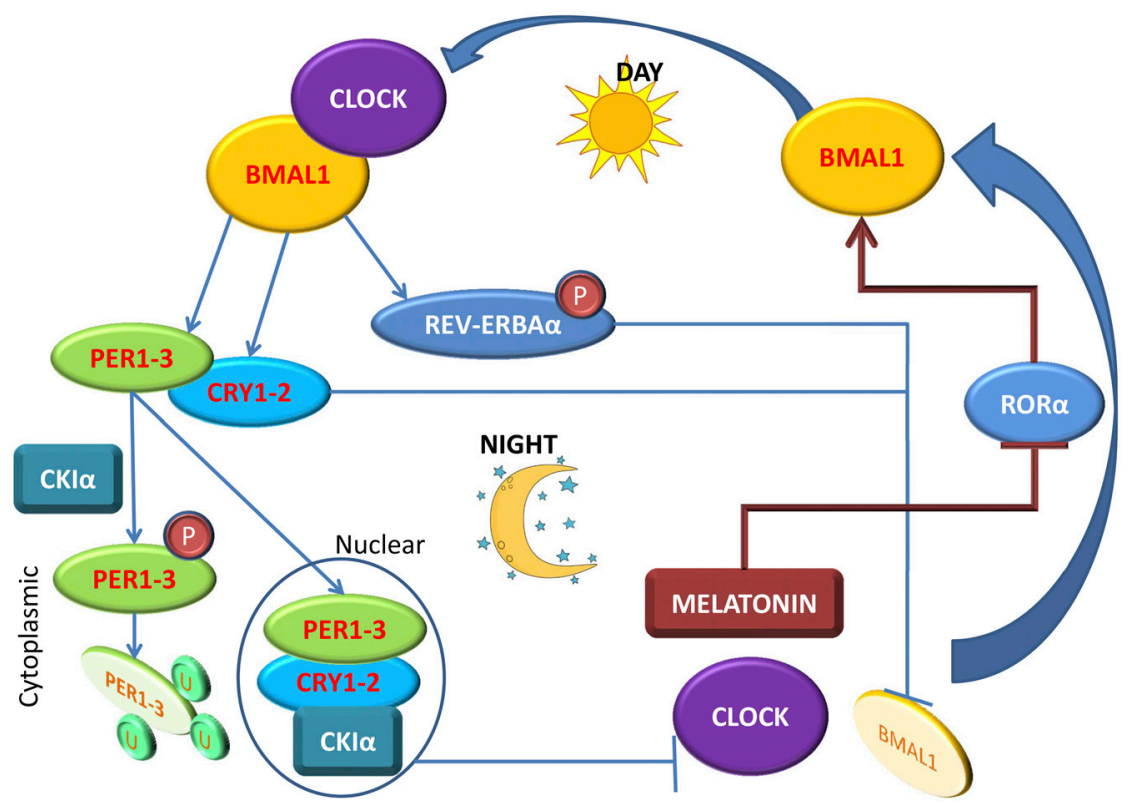

\section{Figure 3}

24-h cycle of the circadian clock. The expression of Clock itself does not significantly vary during the 24-h cycle, but it is only one of few genes in this group that does not. Major regulation of the circadian clock is mediated by the orphan nuclear receptors ROR $\alpha$ and REV-ERBA $\alpha$, which determine the expression of Bmal1 (also known as ARNTL), the key binding partner of Clock. During the day, the Clock-Bmal1 dimer transcribes genes that result in the synthesis of Per and Cry, as well as REV-ERBA $\alpha$. As the day progresses, Per and Cry dimerizes and forms a stable complex that translocates to the nucleus. Any free Per remaining in the cytoplasm is phosphorylated by CKIع, which causes it to be ubiquitinated and degraded. As night falls, the Per/Cry oligomer complex in the nucleus disrupts the formation of the Clock-Bmal1 heterodimer, which then stops producing Per and Cry. In addition, REVERBA $\alpha$ is phosphorylated by GSK3 $\beta$, which stabilizes the protein, and allow it to transcriptionally repress the expression of Bmal1. Bmal1 levels are also suppressed when melatonin levels increase in the circulation, which inhibits the expression of ROR $\alpha$ that positively regulates Bmal1 expression. Decrease in Bmal1 further disrupts the Clock-Bmal1 complex and prevents the transcription of target genes, including Per and Cry. As REV-ERBA $\alpha$ levels in the cell, and melatonin levels in the circulation, decrease early in the morning, Bmal1 synthesis is resumed. Further, Per and Cry levels in the nucleus also fall off due to decreased synthesis, and Clock-Bmal1 complexes resume, which then allows the circadian clock to move forward. P denotes protein phosphorylation, $\mathrm{U}$ denotes protein ubiquitination.

associated with ageing, etc.) (Sanchez-Barcelo et al. 2010). Melatonin seems to facilitate sleep in insomniac patients in some cases (Rohr \& Herold 2002). However, the National Sleep Foundation warns that 'the correct dosage, method and time of day it is taken must be appropriate to the sleep problem'.

\section{Relation between the circadian clock and androgens}

Circadian rhythms have been shown to play an important role in the expression of androgens, and studies show high levels of testosterone production in early mornings in healthy men that decline as the day progresses leading to lower levels by the evening (Cooke et al. 1993). As a result, in the diagnosis of hypogonadism in males, it is recommended that testosterone levels be assessed in the morning before $00: 10 \mathrm{~h}$. This decline was coincident with the initial rise in the concentration of cortisol (Cooke et al. 1993). Surprisingly, the early morning spike in testosterone levels characteristic of young men was blunted in old age (Bremner et al. 1983). Additional studies indicated that an adrenal androgen-regulating system was impaired in the older subjects (Montanini et al. 1988), especially over the age of 70 (Diver et al. 2003). A comparison of young (3-month) and aged (18- and 24-month) rats showed that expression of several clock genes (Bmal1, Per1, Per2, Per3 and Rev-ErbA $\alpha$ ) were reduced in the 24-month-old group compared with the younger groups (Baburski et al. 2016) (Fig. 4). These results seem to suggest that the reduced levels of the clock genes in aged males may be responsible for the loss of circadian rhythmicity observed in ageing.

In support of the above observations, delayed peak androgen production was identified in night shift workers compared with day workers (Papantoniou et al. 2015b), and may have contributed in part to the increased risk for CaP observed in night shift workers (Kubo et al. 2006, Papantoniou et al. 2015a, Rao et al. 2015). Significantly, the rhythmicity of Per2 mRNA levels in the blood depended on the period of activity of the subjects, therefore, it was

Published by Bioscientifica Ltd. 


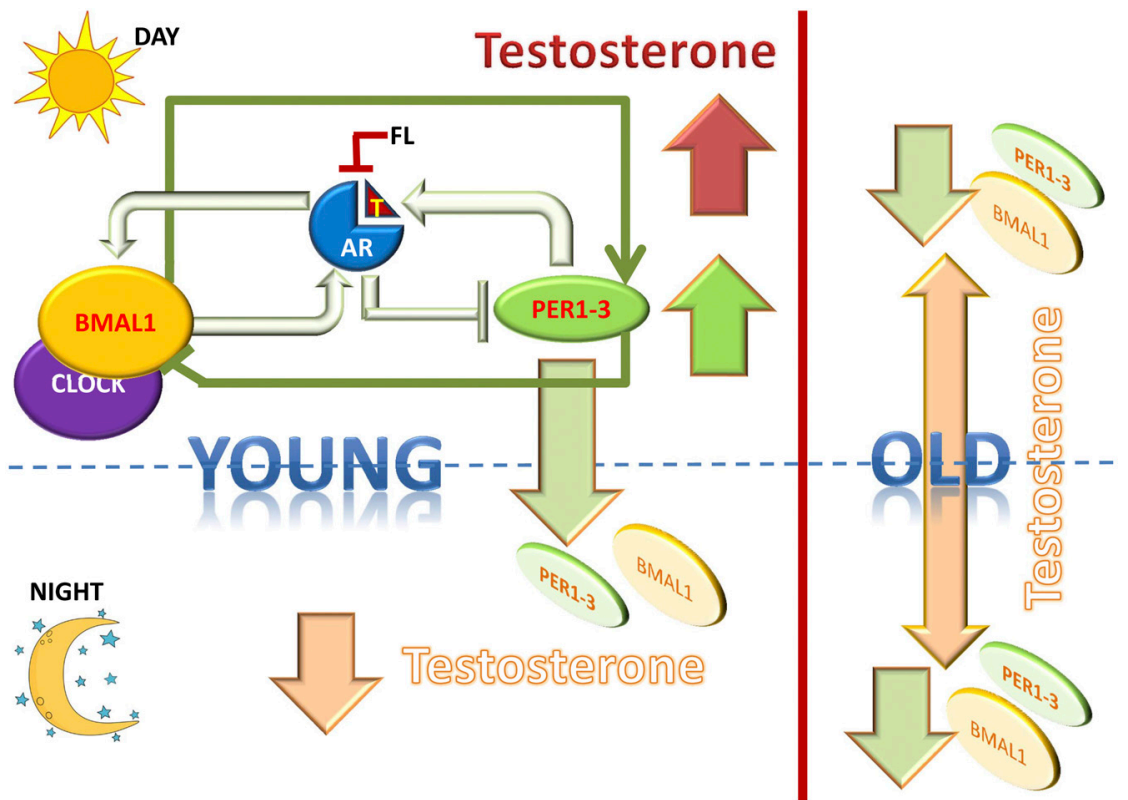

Figure 4

Circadian regulation of testosterone production in young and old men. Healthy young men demonstrate high levels of testosterone production in early mornings that decline as the day progresses leading to lower levels by the evening. During the day, Per complexes promote testosterone production, as did Bmal1; the produced testosterone binds to and activates the androgen receptor (AR), but as night falls, activated AR suppresses Per levels, thereby decreasing testosterone production and deactivates the AR. This in turn suppressed Bmal1 levels, further preventing Per expression. As Per levels increase once more the next morning, along with Bmal1 levels, testosterone production is renewed. However, several clock genes (Bmal1, Per1, Per2, Per3 and Rev-ErbA $\alpha$ ) are reduced in older males compared with younger ones, resulting in the loss of circadian rhythmicity in testosterone synthesis observed in ageing males. T, testosterone. higher in the morning for day shift workers, similar to the general population, but higher in the evening for night shift workers (Fang et al. 2015). This shift in Per2 levels was coincident with testosterone synthesis, suggesting strong association between androgen production and the expression of Per2. Additional reports showed that Bmal1 and Clock, but not Per2 and Nr1d1/Rev-ErbA $\alpha$, are downregulated by testosterone deficiency (Kawamura et al. 2014). Thus, it is likely that Per2 drives testosterone levels. This observation was borne out by another study in rat prostate mesenchymal cells, which showed that neither testosterone nor DHT caused any change in Per2 activity (Yoshida et al. 2010). On the other hand, the same study showed that the anti-androgen flutamide, which is used for the treatment of advanced CaP, upregulated the amplitude of circadian Per2 oscillations in a dose-dependent manner (Yoshida et al. 2010). As flutamide binds to and inhibits the AR, it is possible that AR transcriptional activity, through activation of a downstream target of the AR, regulate Per2 activity and levels (Fig. 4).

A significant relation exists between other clock genes and testosterone levels as well. Studies in rodent models revealed that the AR is concentrated in the SCN core in male mice (Iwahana et al. 2008). Similar to Per2, Per1 also inhibited AR transactivation and diminished the expression of AR target genes following DHT stimulation; while Per1 itself is regulated by androgens in CaP cells (Cao et al. 2009). Both male and female Bmal1 knockout (K/O) mice are infertile (Alvarez et al. 2008). Male Bmal1 $\mathrm{K} / \mathrm{O}$ mice had low testosterone and high luteinizing hormone serum concentrations, suggesting a role for Bmal1 in androgen production, while in turn, Bmal1 and Clock are downregulated by testosterone deficiency (Kawamura et al. 2014). Importantly, Leydig cells, which produce testosterone, rhythmically express Bmal1 protein (Alvarez et al. 2008). Further evidence that the Bmal1Clock heterodimer is involved in testosterone production and AR transactivation came from studies using mice homozygous for a dominant-negative allele of the Clock gene (Clock $(\Delta 19 / \Delta 19))$, which have slightly but significantly decreased male fertility (Liang et al. 2013). Taken together, these reports point to a process by which feedback loops may exist between the AR axis and the clock genes in males (Fig. 4).

\section{Clock genes and prostate cancer regulation}

Clock genes are known to be directly involved in the regulation of tumorigenesis in the prostate and other organs. Per1 is downregulated in human CaP samples compared with normal prostates (Cao et al. 2009). On the other hand, overexpression of Per1 in CaP cells resulted in significant growth inhibition and apoptosis (Cao et al. 2009). Other studies found that Clock and Per2 protein levels were downregulated whereas Bmal1 protein levels were upregulated in CaP cells, compared with normal prostate cells (Jung-Hynes et al. 2010). Overexpression of Per2 reduced CaP cell growth and viability. Interestingly, melatonin treatment increased Per2 and Clock and reduced Bmal1, thereby causing resynchronization of oscillatory circadian rhythm genes

Published by Bioscientifica Ltd. 
Table 1 Association of various single-nucleotide polymorphisms (SNP) in known circadian-related genes with susceptibility to CaP (Zhu et al. 2009) or with fatal CaP (Markt et al. 2015).

\begin{tabular}{l} 
Clock gene \\
\hline PER1 \\
PER2 \\
PER3 \\
$C R Y 1$ \\
$C R Y 2$ \\
$C K I E$ \\
$B M A L 1$ (ARNTL) \\
CLOCKINPAS2
\end{tabular}

\begin{tabular}{l} 
SNP associated with susceptibility to CaP \\
\hline rs885747 and rs2289591 \\
rs7602358 \\
rs1012477 \\
rs12315175 \\
rs2292912 \\
rs1534891 \\
rs7950226 \\
rs11133373, rs1369481, rs895521, and rs17024926
\end{tabular}

SNP associated with fatal CaP
rs2289591
rs10462023
rs7297614, rs1921126 and rs12315175
rs969485
rs3754674 and rs10206435

in CaP cells (Jung-Hynes et al. 2010). It appears that resynchronization of the clock genes may have tumoursuppressive effects in CaP cells.

Population-based genetic associations studies which genotyped single-nucleotide polymorphisms (SNP) in known circadian-related genes showed that at least one SNP in each of the core circadian genes was significantly associated with susceptibility to CaP (Zhu et al. 2009), and quite a few were associated with fatal CaP (Markt et al. 2015) (Table 1). However, there are variations in the strength of association between fatal CaP and these SNPs among different cohorts showing variability in different patient cohorts (Markt et al. 2015). Taken together, these reports illustrate a possible role of multiple clock genes in the regulation of $\mathrm{CaP}$ progression and development.

\section{Melatonin regulation of prostate carcinogenesis}

Recent studies showed that patients with high melatonin levels or a high melatonin/cortisol ratio were less likely to develop $\mathrm{CaP}$ or experience $\mathrm{CaP}$ progression (Tai et al. 2016). Comparison of serum levels of melatonin in elderly men with benign prostatic hyperplasia $(\mathrm{BPH})$, prostatic intraepithelial neoplasia (PIN) and localized CaP, as well as in normal adult men without $\mathrm{CaP}$, demonstrated that melatonin induced significant circadian rhythms in normal men and patients with BPH (enlarged prostate) and PIN (considered to be a precursor for prostate cancer) but not in patients with CaP (Bartsch et al. 1985). In support of these reports, a rodent model affirmed that melatonin suppresses prostate tumorigenesis (Toma et al. 1987).

However, further analysis found that, while afternoon melatonin administration induced tumour remission in castrated rodents, continuous melatonin administration did not have any significant effect on CaP tumours (Buzzell 1988), suggesting that melatonin is only effective when administered in synchronization with the patient's natural circadian cycle. Further, the study also emphasized that melatonin is more effective with low AR activity. In a study of 186 patients with previously untreated metastases from colorectal cancer, 93 patients were assigned chronotherapy with oxaliplatin, fluorouracil and folinic acid and 93 were assigned constant-rate infusion via multichannel programmable ambulatory pumps (Levi et al. 1997). An objective response was obtained in 47 (51\%) of the chronotherapy group, and in $27(29 \%)$ of the constant-rate group. Chronotherapy reduced five-fold the rate of severe mucosal toxicity and halved that of functional impairment from peripheral sensitive neuropathy (Levi et al. 1997). In vitro studies demonstrated higher growth inhibitory efficacy of melatonin not only in the absence of androgens (Siu et al. 2002) but also in the presence of oestrogens which are known to suppress androgen production (Lupowitz \& Zisapel 1999). Thus, there is possible interaction between the melatonin-dependent pathway and the AR axis that likely antagonize each other.

The growth-suppressive effects of melatonin seems to be dependent on the GPCRs MT1/Mel1A and MT2/ Mel1B receptors (Moretti et al. 2000, Xi et al. 2000, 2001); whereas in the absence of these receptors, melatonin does not appear to have a tumour-suppressive role. The fact that melatonin's effects on tumour suppression were only observed when melatonin was used in a circadian manner (afternoon administration), but not when it was continuous, suggest that continuous melatonin administration causes degradation of the melatonin receptors likely via a feedback mechanism, as is often seen in many GPCRs. Significantly, MT1 and MT2 are highly expressed in AR null cells (Gilad et al. 1999, Marelli et al. 2000, Sainz et al. 2005), and in 22Rv1 cells expressing high levels of alternately spliced AR variants (and low levels of full-length AR) (Tam et al. 2007), but not in cells expressing high AR levels (Moretti et al. 2000). These results 


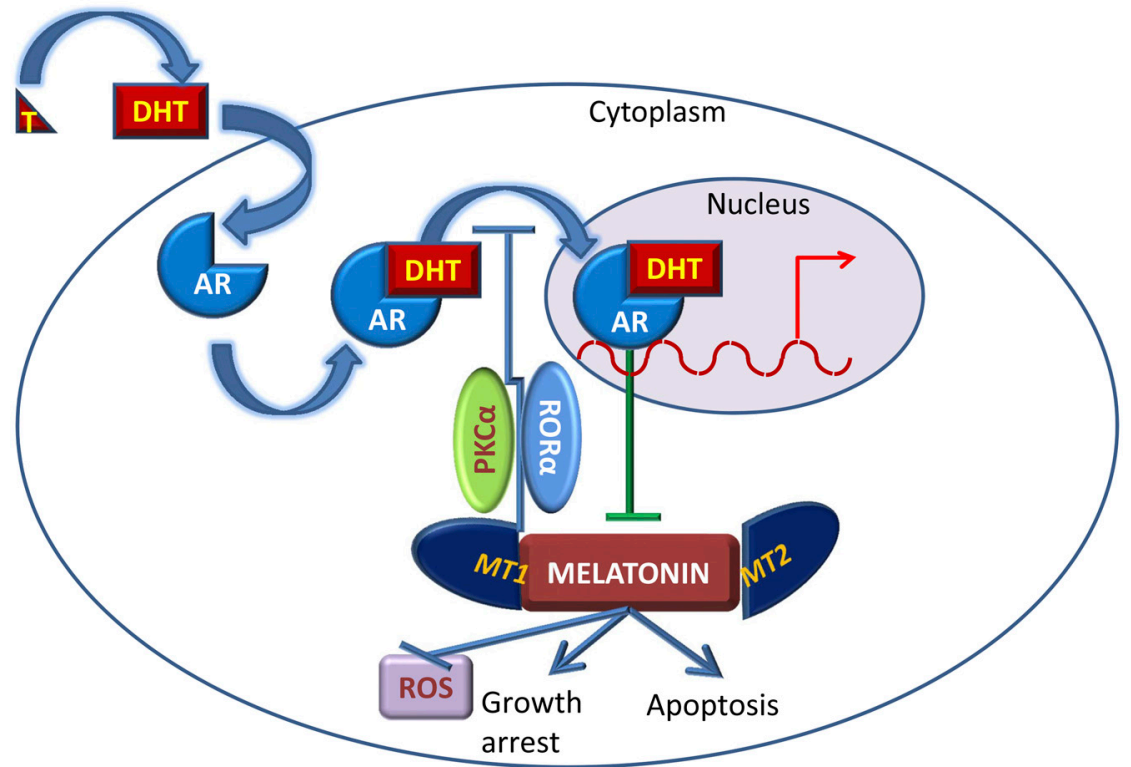

\begin{abstract}
Figure 5
Negative feedback loop between melatonin and the androgen receptor. Testosterone $(T)$ is converted to dihydrotestosterone (DHT), which in the prostate, binds to the androgen receptor (AR) in the cytoplasm of prostate-derived cells, including prostate cancer. DHT binding activates the $A R$, which then translocates to the nucleus and binds to androgen response elements (ARE) in the target genes, thereby stimulating their transcription. AR transcriptional activity represses the expression of the melatonin receptors MT1 and $\mathrm{MT} 2$, thereby preventing their binding to melatonin. This prevents melatonin's ability to induce growth arrest and apoptosis, and to prevent oxidative stress. In turn, melatonin and its receptors inhibit AR translocation to the nucleus, not only by preventing testosterone conversion to DHT but also by mechanisms involving PKC $\alpha$ or ROR $\alpha$.
\end{abstract}

suggest that AR activity suppresses the expression of the melatonin receptors. Therefore, melatonin is perhaps more effective in CaP models of castration where $\mathrm{AR}$ activity is low, allowing MT1/2 expression, which can then bind melatonin (Fig. 5).

In turn, it was reported that melatonin inhibits AR localization in the nucleus, where it is active, thereby suppressing AR activity (Lupowitz et al. 2001, Rimler et al. 2001, 2002a) and preventing AR binding to its target gene (Rimler et al. 2002b). Other studies suggest that melatonin prevents testosterone conversion to DHT, a strong AR ligand (Philo \& Berkowitz 1988). Melatonin's effect on the AR has been suggested to be mediated by the inhibition of the RZR/ROR receptors (Karasek \& Pawlikowski 1999), while inhibition of AR nuclear translocation by melatonin was likely via a PKC $\alpha$-dependent mechanism (Sampson et al. 2006). Thus, melatonin and the AR pathway inhibit each other (Fig. 5), likely to gain control of the downstream targets leading to cell cycle progression and apoptosis. Whether the tumour progresses or not will depend on which pathway gains control in the end.

Melatonin's effects on growth arrest are mediated by PKC $\alpha$ (Tam et al. 2008), and by aldo-ketoreductase (AKR) and prostaglandin F-synthase (PGFS)-dependent pathways (Byrns et al. 2008), whereas its effects on cell death required elevation of p21 (Park et al. 2009), p27Kip1 (Tam \& Shiu 2011), activation of TNF $\alpha$ - and NF-kBdependent pathways (Sainz et al. 2008, Rodriguez-Garcia et al. 2013, Shiu et al. 2013) and JNK and p38MAPK activation (Joo \& Yoo 2009). Melatonin inhibition of HIF1 $\alpha$ signalling and reactive oxygen species generation has also been established (Park et al. 2009, Cho et al. 2011,
Paroni et al. 2014). Several microRNAs (miRNAs) including miR3195 and miR374b were significantly upregulated while other miRNAs were downregulated in melatonintreated cells under hypoxia compared with untreated control (Sohn et al. 2015). In addition to hypoxia and androgen deprivation, melatonin also seems to sensitize CaP cell lines to cell death under hypoglycaemic conditions (Kabasakal et al. 2011, Gobbo et al. 2015).

As melatonin was effective in tumour suppression in castrated rodents, a Phase II clinical trial was initiated to test the efficacy of melatonin in conjunction with a LHRH agonist vs the LHRH agonist alone (Lissoni et al. 1997). Men treated with the combination demonstrated a decrease in PSA serum levels greater than 50\% in 57\% patients, a normalization of platelet number in patients with persistent thrombocytopaenia before study, and a survival longer than 1 year in 64\% patients (Lissoni et al. 1997). Therefore, it appears that melatonin may actually prolong the effects of LHRH agonists in men with advanced CaP. In support of the involvement of the melatonin receptor in the suppression of carcinogenesis by melatonin, a case report of a patient whose prostate tissue expressed the melatonin receptors demonstrated efficacy of melatonin in suppressing tumour progression (Shiu et al. 2003).

\section{Effect of the circadian clock in hormone and chemotherapy}

While melatonin is the direct effector of the circadian clock, our growing understanding of the circadian rhythm has produced various strategies to increase

Published by Bioscientifica Ltd 
the effectiveness of cancer treatment. Hot flashes are a common side effect of ADT using LHRH agonists in men with advanced CaP. A recent study demonstrated that there were significant 24 -h circadian rhythms of hot flashes following ADT administration (Hanisch \& Gehrman 2011) where the peak of the rhythms occurred in early afternoon. As altered circadian rhythms have been identified in untreated $\mathrm{CaP}$ patients, the authors conclude that the acrophases of hot flashes and elevated activity levels may represent a normalization of circadian rhythms following ADT (Hanisch \& Gehrman 2011).

Recently, a retrospective study testing disease control and treatment-related toxicity in patients undergoing high-dose radiotherapy (HDRT) (median 78 Gy) for CaP evaluated those receiving daytime treatment (before 17:00h) ( $n=267)$ vs evening treatment (after 17:00 h) group ( $n=142$ ) (Hsu et al. 2016). This study found that evening HDRT was significantly associated with worse freedom from $\geq$ grade 2 late GI complications (hazard ratio $=2.96 ; P<0.001$ ), especially in patients older than 70 years. Moreover, biochemical failure-free survival was worse in the evening group than the daytime group (72\% vs $85 \%$, hazard ratio $=1.95, P=0.05$ ) (Hsu et al. 2016). No known circadian-based trials of hormone and chemotherapeutic agents that are effective in CRPC patients have been reported as yet. Hormone-refractory metastatic $\mathrm{CaP}$ has been treated with circadian-timed fluorodeoxyuridine (FUDR) chemotherapy; however, without objective response (Rajagopalan et al. 1998). The lack of objective response, of course, could result from the lack of efficacy of FUDR in CaP patients.

As chronomodulation was not implemented in many $\mathrm{CaP}$ trials of chemotherapeutic agents, circadian-timed delivery of chemotherapeutic agents in other cancers will be examined. In 1985, 31 patients with advanced ovarian cancer received eight monthly courses of doxorubicin (adriamycin) that were followed $12 \mathrm{~h}$ later by cisplatin, with doxorubicin randomly administered at either 06:00 h or 18:00h (Hrushesky 1985). Those receiving doxorubicin in the evening and cisplatin in the morning required reductions in dosage and delays in treatment (indicative of greater toxicity), compared with those receiving doxorubicin in the morning and cisplatin in the evening (Hrushesky 1985). A similar study concluded that the combination (doxorubicin + cisplatin) is active against advanced ovarian cancer, but that its toxicities can be significantly decreased by dosing doxorubicin in the early morning and cisplatin in the late afternoon (Levi et al. 1990).
Thereafter, this schedule (doxorubicin in the early morning and cisplatin in the late afternoon) has been used in studies on endometrial and bladder cancer patients, with considerable success (reviewed in Kobayashi et al. (2002)). Similar success was achieved in patients with metastatic renal cell carcinoma receiving fluorodeoxyuridine (FUDR) when delivered by a circadianmodified infusion schedule, in which $68 \%$ of the daily dose was administered between 15:00 h and 21:00 h, compared with continuous infusion (Hrushesky et al. 1990). As mentioned earlier, a study of chronomodulated infusion (administered to coincide with relevant circadian rhythms) of oxaliplatin, fluorouracil and folinic acid compared with a constant-rate infusion method demonstrated that chronotherapy was significantly less toxic and more effective than constant-rate infusion in patients with metastatic colorectal cancer (Levi et al. 1997). While no studies on the use of chronomodulation in hormone and chemotherapy in $\mathrm{CaP}$ patients have been reported, the above studies in ovarian, endometrial, bladder, renal and colorectal cancer patients suggest that the use of chronomodulation in CaP patients may yield considerable benefit as well.

\section{Conclusion}

This review concisely describes current knowledge of the mechanisms by which the circadian clock interacts with AR-signalling pathway. While in normal individuals, the clock genes, especially Per1/per2 and Bmal1 were expressed in a circadian rhythmic manner, this rhythmicity was lost in CaP patients, while the neurohormone melatonin, which can regulate Bmal1 levels, restored circadian function. We provide evidence that melatonin reduced cytotoxicity in individuals receiving chemo- and hormonal therapy, and sensitized patients to LHRH agonists. A recent study suggests that chronomodulation of radiation therapy benefit $\mathrm{CaP}$ patients receiving radiotherapy in the morning compared with those receiving the treatment in the evening. Given the success of chronomodulation in the treatment of other cancers with chemotherapy, the studies references here hypothesize an improvement in outcome and a reduction in toxicity if $\mathrm{CaP}$ patients were to be tested for chronodependence in chemo- and hormonal therapy.

\section{Declaration of interest}

The authors declare no conflict of interest. The work reported here does not represent the views or opinions of the Department of Veteran Affairs or the United States Government.

Published by Bioscientifica Ltd. 


\section{Funding}

This work was supported by a Biomedical Laboratory Research \& Development (BLRD) Merit Award (I01BX000400, P M G) from the Department of Veterans Affairs, and by Award R01CA185509 (P M G) from the National Institutes of Health.

\section{References}

Alvarez JD, Hansen A, Ord T, Bebas P, Chappell PE, Giebultowicz JM, Williams C, Moss S \& Sehgal A 2008 The circadian clock protein BMAL1 is necessary for fertility and proper testosterone production in mice. Journal of Biological Rhythms 23 26-36. (doi:10.1177/0748730407311254)

Asghari MH, Moloudizargari M, Bahadar H \& Abdollahi M 2016 A review of the protective effect of melatonin in pesticide-induced toxicity. Expert Opinion on Drug Metabolism and Toxicology 1-10. (doi:10.1080/17425255.2016.1214712)

Baburski AZ, Sokanovic SJ, Bjelic MM, Radovic SM, Andric SA \& Kostic TS 2016 Circadian rhythm of the Leydig cells endocrine function is attenuated during aging. Experimental Gerontology 73 5-13. (doi:10.1016/j.exger.2015.11.002)

Band PR, Le ND, Fang R, Deschamps M, Coldman AJ, Gallagher RP \& Moody J 1996 Cohort study of Air Canada pilots: mortality, cancer incidence, and leukemia risk. American Journal of Epidemiology 143 137-143. (doi:10.1093/oxfordjournals.aje.a008722)

Bartsch C, Bartsch H, Fluchter SH, Attanasio A \& Gupta D 1985 Evidence for modulation of melatonin secretion in men with benign and malignant tumors of the prostate: relationship with the pituitary hormones. Journal of Pineal Research 2 121-132. (doi:10.1111/j.1600-079X.1985.tb00633.x)

Boutin JA, Audinot V, Ferry G \& Delagrange P 2005 Molecular tools to study melatonin pathways and actions. Trends in Pharmacological Sciences 26 412-419. (doi:10.1016/j.tips.2005.06.006)

Bremner WJ, Vitiello MV \& Prinz PN 1983 Loss of circadian rhythmicity in blood testosterone levels with aging in normal men. Journal of Clinical Endocrinology and Metabolism 56 1278-1281. (doi:10.1210/ jcem-56-6-1278)

Brown CE, Warren S, Chute RN, Ryan KJ \& Todd RB 1979 Hormonally induced tumors of the reproductive system of parabiosed male rats. Cancer Research 39 3971-3976.

Buzzell GR 1988 Studies on the effects of the pineal hormone melatonin on an androgen-insensitive rat prostatic adenocarcinoma, the Dunning R 3327 HIF tumor. Journal of Neural Transmission 72 131-140. (doi:10.1007/BF01250236)

Byrns MC, Steckelbroeck S \& Penning TM 2008 An indomethacin analogue, $\mathrm{N}$-(4-chlorobenzoyl)-melatonin, is a selective inhibitor of aldo-keto reductase 1C3 (type 2 3alpha-HSD, type 5 17beta-HSD, and prostaglandin $\mathrm{F}$ synthase), a potential target for the treatment of hormone dependent and hormone independent malignancies. Biochemical Pharmacology 75 484-493. (doi:10.1016/j. bcp.2007.09.008)

Cao Q, Gery S, Dashti A, Yin D, Zhou Y, Gu J \& Koeffler HP 2009 A role for the clock gene per1 in prostate cancer. Cancer Research 69 7619-7625. (doi:10.1158/0008-5472.CAN-08-4199)

Cho SY, Lee HJ, Jeong SJ, Lee HJ, Kim HS, Chen CY, Lee EO \& Kim SH 2011 Sphingosine kinase 1 pathway is involved in melatonininduced HIF-1alpha inactivation in hypoxic PC-3 prostate cancer cells. Journal of Pineal Research 51 87-93. (doi:10.1111/j.1600-079X.2011.00865.x)

Cooke RR, McIntosh JE \& McIntosh RP 1993 Circadian variation in serum free and non-SHBG-bound testosterone in normal men: measurements, and simulation using a mass action model. Clinical Endocrinology 39 163-171. (doi:10.1111/j.1365-2265.1993. tb01769.x)
Demir MG, Altintoprak N, Aydin S, Kosemihal E \& Basak K 2015 Effect of transtympanic injection of melatonin on cisplatin-induced ototoxicity. Journal of International Advanced Otology 11 202-206. (doi:10.5152/iao.2015.1094)

Denmeade S, Sokoll L, Darlymple S, Rosen D \& Gady A 2003 Dissociation between androgen responsiveness for malignant growth vs expression of prostate specific markers PSA, hK2 and PSMA in human prostate cancer models. Prostate 54 249-257. (doi:10.1002/ pros.10199)

Diver MJ, Imtiaz KE, Ahmad AM, Vora JP \& Fraser WD 2003 Diurnal rhythms of serum total, free and bioavailable testosterone and of SHBG in middle-aged men compared with those in young men. Clinical Endocrinology 58 710-717. (doi:10.1046/ j.1365-2265.2003.01772.x)

Esteban-Zubero E, Alatorre-Jimenez MA, Lopez-Pingarron L, Reyes-Gonzales MC, Almeida-Souza P, Cantin-Golet A, Ruiz-Ruiz FJ, Tan DX, Garcia JJ \& Reiter RJ 2016 Melatonin's role in preventing toxin-related and sepsis-mediated hepatic damage: A review. Pharmacological Research 105 108-120. (doi:10.1016/j. phrs.2016.01.018)

Fang MZ, Ohman-Strickland P, Kelly-McNeil K, Kipen H, Crabtree BF, Lew JP \& Zarbl H 2015 Sleep interruption associated with house staff work schedules alters circadian gene expression. Sleep Medicine 16 1388-1394. (doi:10.1016/j.sleep.2015.06.011)

Fu L \& Lee CC 2003 The circadian clock: pacemaker and tumour suppressor. Nature Reviews Cancer 3 350-361. (doi:10.1038/nrc1072)

Gann PH, Hennekens CH, Ma J, Longcope C \& Stampfer MJ 1996 Prospective study of sex hormone levels and risk of prostate cancer. Journal of the National Cancer Institute 88 1118-1126. (doi:10.1093/ jnci/88.16.1118)

Gilad E, Laufer M, Matzkin H \& Zisapel N 1999 Melatonin receptors in PC3 human prostate tumor cells. Journal of Pineal Research 26 211-220. (doi:10.1111/j.1600-079X.1999.tb00586.x)

Gobbo MG, Dizeyi N, Abrahamsson PA, Bertilsson PA, Masiteli VS Pytlowanciv EZ, Taboga SR \& Goes RM 2015 Influence of melatonin on the proliferative and apoptotic responses of the prostate under normal and hyperglycemic conditions. Journal of Diabetes Research 2015 538529. (doi:10.1155/2015/538529)

Griffin EA Jr, Staknis D \& Weitz CJ 1999 Light-independent role of CRY1 and CRY2 in the mammalian circadian clock. Science 286 768-771. (doi:10.1126/science.286.5440.768)

Hanisch LJ \& Gehrman PR 2011 Circadian rhythm of hot flashes and activity levels among prostate cancer patients on androgen deprivation therapy. Aging Males 14 243-248. (doi:10.3109/13685538 .2011.582528)

Hill SM, Frasch T, Xiang S, Yuan L, Duplessis T \& Mao L 2009 Molecular mechanisms of melatonin anticancer effects. Integrative Cancer Therapies 8 337-346. (doi:10.1177/1534735409353332)

Hrushesky WJ 1985 Circadian timing of cancer chemotherapy. Science 228 73-75. (doi:10.1126/science.3883493)

Hrushesky WJ, von Roemeling R, Lanning RM \& Rabatin JT 1990 Circadian-shaped infusions of floxuridine for progressive metastatic renal cell carcinoma. Journal of Clinical Oncology 8 1504-1513.

Hsu DS, Zhao X, Zhao S, Kazantsev A, Wang RP, Todo T, Wei YF \& Sancar A 1996 Putative human blue-light photoreceptors hCRY1 and hCRY2 are flavoproteins. Biochemistry 35 13871-13877. (doi:10.1021/ bi962209o)

Hsu FM, Hou WH, Huang CY, Wang CC, Tsai CL, Tsai YC, Yu HJ, Pu YS \& Cheng JC 2016 Differences in toxicity and outcome associated with circadian variations between patients undergoing daytime and evening radiotherapy for prostate adenocarcinoma. Chronobiology International 33 210-219. (doi:10.3109/07420528.2015.1130049)

Iwahana E, Karatsoreos I, Shibata S \& Silver R 2008 Gonadectomy reveals sex differences in circadian rhythms and suprachiasmatic nucleus androgen receptors in mice. Hormones and Behavior 53 422-430. (doi:10.1016/j.yhbeh.2007.11.014) 
Joo SS \& Yoo YM 2009 Melatonin induces apoptotic death in LNCaP cells via p38 and JNK pathways: therapeutic implications for prostate cancer. Journal of Pineal Research 47 8-14. (doi:10.1111/ j.1600-079X.2009.00682.x)

Jung-Hynes B, Huang W, Reiter RJ \& Ahmad N 2010 Melatonin resynchronizes dysregulated circadian rhythm circuitry in human prostate cancer cells. Journal of Pineal Research 49 60-68. (doi:10.1111/j.1600-079x.2010.00767.x)

Kabasakal L, Sener G, Balkan J, Dogru-Abbasoglu S, Keyer-Uysal M \& Uysal M 2011 Melatonin and beta-glucan alone or in combination inhibit the growth of dunning prostatic adenocarcinoma. Oncology Research 19 259-263. (doi:10.3727/096504011X13021877989748)

Karasek M \& Pawlikowski M 1999 Antiproliferative effects of melatonin and CGP 52608. Biological Signals and Receptors 8 75-78. (doi:10.1159/000014572)

Kawamura M, Tasaki H, Misawa I, Chu G, Yamauchi N \& Hattori MA 2014 Contribution of testosterone to the clock system in rat prostate mesenchyme cells. Andrology 2 225-233. (doi:10.1111/ j.2047-2927.2013.00161.x)

Ko C \& Takahashi S 2006 Molecular components of the mammalian circadian clock. Human Molecular Genetics 15 271-277. (doi:10.1093/ $\mathrm{hmg} / \mathrm{ddl207)}$

Kobayashi M, Wood PA \& Hrushesky WJ 2002 Circadian chemotherapy for gynecological and genitourinary cancers. Chronobiology International 19 237-251. (doi:10.1081/CBI-120002600)

Kubo T, Ozasa K, Mikami K, Wakai K, Fujino Y, Watanabe Y, Miki T, Nakao M, Hayashi K, Suzuki K, et al. 2006 Prospective cohort study of the risk of prostate cancer among rotating-shift workers: findings from the Japan collaborative cohort study. American Journal of Epidemiology 164 549-555. (doi:10.1093/aje/kwj232)

Levi F, Benavides M, Chevelle C, Le Saunier F, Bailleul F, Misset JL, Regensberg C, Vannetzel JM, Reinberg A \& Mathe G 1990 Chemotherapy of advanced ovarian cancer with 4'-O-tetrahydropyranyl doxorubicin and cisplatin: a randomized phase II trial with an evaluation of circadian timing and doseintensity. Journal of Clinical Oncology 8 705-714.

Levi F, Zidani R \& Misset JL 1997 Randomised multicentre trial of chronotherapy with oxaliplatin, fluorouracil, and folinic acid in metastatic colorectal cancer. International Organization for Cancer Chronotherapy. Lancet 350 681-686. (doi:10.1016/S01406736(97)03358-8)

Liang X, Cheng S, Jiang X, He X, Wang Y, Jiang Z, Hou W, Li S, Liu Y \& Wang Z 2013 The noncircadian function of the circadian Clock gene in the regulation of male fertility. Journal of Biological Rhythms $\mathbf{2 8}$ 208-217. (doi:10.1177/0748730413486873)

Lissoni P, Cazzaniga M, Tancini G, Scardino E, Musci R, Barni S, Maffezzini M, Meroni T, Rocco F, Conti A, et al. 1997 Reversal of clinical resistance to LHRH analogue in metastatic prostate cancer by the pineal hormone melatonin: efficacy of LHRH analogue plus melatonin in patients progressing on LHRH analogue alone. European Urology 31 178-181.

Liu C, Weaver DR, Strogatz SH \& Reppert SM 1997 Cellular construction of a circadian clock: period determination in the suprachiasmatic nuclei. Cell 91 855-860. (doi:10.1016/S0092-8674(00)80473-0)

Lupowitz Z, Rimler A \& Zisapel N 2001 Evaluation of signal transduction pathways mediating the nuclear exclusion of the androgen receptor by melatonin. Cellular and Molecular Life Sciences 58 2129-2135. (doi:10.1007/PL00000842)

Lupowitz Z \& Zisapel N 1999 Hormonal interactions in human prostate tumor LNCaP cells. Journal of Steroid Biochemistry and Molecular Biology 68 83-88. (doi:10.1016/S0960-0760(98)00164-2)

Marelli MM, Limonta P, Maggi R, Motta M \& Moretti RM 2000 Growthinhibitory activity of melatonin on human androgen-independent DU 145 prostate cancer cells. Prostate 45 238-244. (doi:10.1002/1097-0045(20001101)45:3<238::AIDPROS6>3.0.CO;2-W)
Markt SC, Valdimarsdottir UA, Shui IM, Sigurdardottir LG, Rider JR, Tamimi RM, Batista JL, Haneuse S, Flynn-Evans E, Lockley SW, et al. 2015 Circadian clock genes and risk of fatal prostate cancer. Cancer Causes and Control 26 25-33. (doi:10.1007/s10552-014-0478-z)

Montanini V, Simoni M, Chiossi G, Baraghini GF, Velardo A, Baraldi E \& Marrama P 1988 Age-related changes in plasma dehydroepiandrosterone sulphate, cortisol, testosterone and free testosterone circadian rhythms in adult men. Hormone Research 29 1-6. (doi:10.1159/000180956)

Moretti RM, Marelli MM, Maggi R, Dondi D, Motta M \& Limonta P 2000 Antiproliferative action of melatonin on human prostate cancer LNCaP cells. Oncology Reports 7 347-351. (doi:10.3892/ or.7.2.347)

Papantoniou K, Castano-Vinyals G, Espinosa A, Aragones N, Perez-Gomez B, Burgos J, Gomez-Acebo I, Llorca J, Peiro R, Jimenez-Moleon JJ, et al. 2015a Night shift work, chronotype and prostate cancer risk in the MCC-Spain case-control study. International Journal of Cancer 137 1147-1157. (doi:10.1002/ijc.29400)

Papantoniou K, Pozo OJ, Espinosa A, Marcos J, Castano-Vinyals G, Basagana X, Juanola Pages E, Mirabent J, Martin J, Such Faro P, et al. $2015 b$ Increased and mistimed sex hormone production in night shift workers. Cancer Epidemiology, Biomarkers and Prevention 24 854-863. (doi:10.1158/1055-9965.EPI-14-1271)

Park JW, Hwang MS, Suh SI \& Baek WK 2009 Melatonin down-regulates HIF-1 alpha expression through inhibition of protein translation in prostate cancer cells. Journal of Pineal Research 46 415-421. (doi:10.1111/j.1600-079X.2009.00678.x)

Paroni R, Terraneo L, Bonomini F, Finati E, Virgili E, Bianciardi P, Favero G, Fraschini F, Reiter RJ, Rezzani R, et al. 2014 Antitumour activity of melatonin in a mouse model of human prostate cancer: relationship with hypoxia signalling. Journal of Pineal Research $\mathbf{5 7}$ 43-52. (doi:10.1111/jpi.12142)

Philo R \& Berkowitz AS 1988 Inhibition of Dunning tumor growth by melatonin. Journal of Urology 139 1099-1102.

Pukkala E, Aspholm R, Auvinen A, Eliasch H, Gundestrup M, Haldorsen T, Hammar N, Hrafnkelsson J, Kyyronen P, Linnersjo A, et al. 2003 Cancer incidence among 10,211 airline pilots: a Nordic study. Aviation, Space, and Environmental Medicine 74 699-706.

Pukkala E, Ojamo M, Rudanko SL, Stevens RG \& Verkasalo PK 2006 Does incidence of breast cancer and prostate cancer decrease with increasing degree of visual impairment. Cancer Causes and Control 17 573-576. (doi:10.1007/s10552-005-9005-6)

Rajagopalan K, Peereboom D, Budd GT, Olencki T, Murthy S, Elson P, McLain D \& Bukowski R 1998 Phase II trial of circadian infusion floxuridine (FUDR) in hormone refractory metastatic prostate cancer. Investigational New Drugs 16 255-258. (doi:10.1023/ A:1006195815320)

Rao D, Yu H, Bai Y, Zheng X \& Xie L 2015 Does night-shift work increase the risk of prostate cancer? A systematic review and metaanalysis. OncoTargets and Therapy 8 2817-2826. (doi:10.2147/OTT. S89769)

Reppert SM \& Weaver DR 2001 Molecular analysis of mammalian circadian rhythms. Annual Review of Physiology 63 647-676. (doi:10.1146/annurev.physiol.63.1.647)

Reppert SM \& Weaver DR 2002 Coordination of circadian timing in mammals. Nature 418 935-941. (doi:10.1038/nature00965)

Rimler A, Culig Z, Levy-Rimler G, Lupowitz Z, Klocker H, Matzkin H, Bartsch G \& Zisapel N 2001 Melatonin elicits nuclear exclusion of the human androgen receptor and attenuates its activity. Prostate 49 145-154. (doi:10.1002/pros.1129)

Rimler A, Culig Z, Lupowitz Z \& Zisapel N 2002a Nuclear exclusion of the androgen receptor by melatonin. Journal of Steroid Biochemistry and Molecular Biology 81 77-84. (doi:10.1016/S09600760(02)00050-X)

Rimler A, Lupowitz Z \& Zisapel N 2002b Differential regulation by melatonin of cell growth and androgen receptor binding to the

Published by Bioscientifica Ltd. 
androgen response element in prostate cancer cells Neuroendocrinology Letters 23 (Supplement 1) 45-49.

Rodriguez-Garcia A, Mayo JC, Hevia D, Quiros-Gonzalez I, Navarro M \& Sainz RM 2013 Phenotypic changes caused by melatonin increased sensitivity of prostate cancer cells to cytokine-induced apoptosis. Journal of Pineal Research 54 33-45. (doi:10.1111/ j.1600-079x.2012.01017.x)

Rohr UD \& Herold J 2002 Melatonin deficiencies in women. Maturitas 41 (Supplement 1) S85-S104. (doi:10.1016/S0378-5122(02)00017-8)

Sainz RM, Mayo JC, Tan DX, Leon J, Manchester L \& Reiter RJ 2005 Melatonin reduces prostate cancer cell growth leading to neuroendocrine differentiation via a receptor and PKA independent mechanism. Prostate 63 29-43. (doi:10.1002/pros.20155)

Sainz RM, Reiter RJ, Tan DX, Roldan F, Natarajan M, Quiros I, Hevia D, Rodriguez C \& Mayo JC 2008 Critical role of glutathione in melatonin enhancement of tumor necrosis factor and ionizing radiation-induced apoptosis in prostate cancer cells in vitro. Journal of Pineal Research 45 258-270. (doi:10.1111/j.1600-079X.2008.00585.x)

Sampson SR, Lupowitz Z, Braiman L \& Zisapel N 2006 Role of protein kinase Calpha in melatonin signal transduction. Molecular and Cellular Endocrinology 252 82-87. (doi:10.1016/j.mce.2006.03.033)

Sanchez-Barcelo EJ, Mediavilla MD, Tan DX \& Reiter RJ 2010 Clinical uses of melatonin: evaluation of human trials. Current Medicinal Chemistry 17 2070-2095. (doi:10.2174/092986710791233689)

Shiu SY, Law IC, Lau KW, Tam PC, Yip AW \& Ng WT 2003 Melatonin slowed the early biochemical progression of hormone-refractory prostate cancer in a patient whose prostate tumor tissue expressed MT1 receptor subtype. Journal of Pineal Research 35 177-182. (doi:10.1034/j.1600-079X.2003.00074.x)

Shiu SY, Leung WY, Tam CW, Liu VW \& Yao KM 2013 Melatonin MT1 receptor-induced transcriptional up-regulation of p27(Kip1) in prostate cancer antiproliferation is mediated via inhibition of constitutively active nuclear factor kappa B (NF-kappaB): potential implications on prostate cancer chemoprevention and therapy. Journal of Pineal Research 54 69-79.

Siu SW, Lau KW, Tam PC \& Shiu SY 2002 Melatonin and prostate cancer cell proliferation: interplay with castration, epidermal growth factor, and androgen sensitivity. Prostate 52 106-122. (doi:10.1002/pros.10098)

So AY, Bernal TU, Pillsbury ML, Yamamoto KR \& Feldman BJ 2009 Glucocorticoid regulation of the circadian clock modulates glucose homeostasis. PNAS 106 17582-17587. (doi:10.1073/pnas.0909733106)

Sohn EJ, Won G, Lee J, Lee S \& Kim SH 2015 Upregulation of miRNA3195 and miRNA374b mediates the anti-angiogenic properties of melatonin in hypoxic PC-3 prostate cancer cells. Journal of Cancer 6 19-28. (doi:10.7150/jca.9591)

Sun ZS, Albrecht U, Zhuchenko O, Bailey J, Eichele G \& Lee CC 1997 RIGUI, a putative mammalian ortholog of the Drosophila period gene. Cell 90 1003-1011. (doi:10.1016/S0092-8674(00)80366-9)

Tai SY, Huang SP, Bao BY \& Wu MT 2016 Urinary melatonin-sulfate/ cortisol ratio and the presence of prostate cancer: a case-control study. Scientific Reports 6 29606. (doi:10.1038/srep29606)
Tam CW, Chan KW, Liu VW, Pang B, Yao KM \& Shiu SY 2008 Melatonin as a negative mitogenic hormonal regulator of human prostate epithelial cell growth: potential mechanisms and clinical significance. Journal of Pineal Research 45 403-412. (doi:10.1111/j.1600-079X.2008.00608.x)

Tam CW, Mo CW, Yao KM \& Shiu SY 2007 Signaling mechanisms of melatonin in antiproliferation of hormone-refractory 22Rv1 human prostate cancer cells: implications for prostate cancer chemoprevention. Journal of Pineal Research 42 191-202. (doi:10.1111/j.1600-079X.2006.00406.x)

Tam CW \& Shiu SY 2011 Functional interplay between melatonin receptor-mediated antiproliferative signaling and androgen receptor signaling in human prostate epithelial cells: potential implications for therapeutic strategies against prostate cancer. Journal of Pineal Research 51 297-312. (doi:10.1111/j.1600-079X.2011.00890.x)

Tei H, Okamura H, Shigeyoshi Y, Fukuhara C, Ozawa R, Hirose M \& Sakaki Y 1997 Circadian oscillation of a mammalian homologue of the Drosophila period gene. Nature 389 512-516. (doi:10.1038/39086)

Toma JG, Amerongen HM, Hennes SC, O’Brien MG, McBlain WA \& Buzzell GR 1987 Effects of olfactory bulbectomy, melatonin, and/or pinealectomy on three sublines of the Dunning R3327 rat prostatic adenocarcinoma. Journal of Pineal Research 4 321-338. (doi:10.1111/ j.1600-079X.1987.tb00870.x)

Welsh DK, Logothetis DE, Meister M \& Reppert SM 1995 Individual neurons dissociated from rat suprachiasmatic nucleus express independently phased circadian firing rhythms. Neuron 14 697-706. (doi:10.1016/0896-6273(95)90214-7)

Xi SC, Siu SW, Fong SW \& Shiu SY 2001 Inhibition of androgensensitive LNCaP prostate cancer growth in vivo by melatonin: association of antiproliferative action of the pineal hormone with $\mathrm{mt} 1$ receptor protein expression. Prostate 46 52-61. (doi:10.1002/1097-0045(200101)46:1<52::AID-PROS1008>3.0.CO;2-Z)

Xi SC, Tam PC, Brown GM, Pang SF \& Shiu SY 2000 Potential involvement of $\mathrm{mt} 1$ receptor and attenuated sex steroid-induced calcium influx in the direct anti-proliferative action of melatonin on androgen-responsive LNCaP human prostate cancer cells. Journal of Pineal Research 29 172-183. (doi:10.1034/j.1600-079X.2000.d01-64.x)

Yoshida K, He PJ, Yamauchi N, Hashimoto S \& Hattori MA 2010 Up-regulation of circadian clock gene Period 2 in the prostate mesenchymal cells during flutamide-induced apoptosis. Molecular and Cellular Biochemistry 335 37-45. (doi:10.1007/s11010-0090238-7)

Zhu Y, Stevens RG, Hoffman AE, Fitzgerald LM, Kwon EM, Ostrander EA, Davis S, Zheng T \& Stanford JL 2009 Testing the circadian gene hypothesis in prostate cancer: a population-based case-control study. Cancer Research 69 9315-9322. (doi:10.1158/0008-5472.CAN-09-0648)

Zhu Y, Zheng T, Stevens RG, Zhang Y \& Boyle P 2006 Does 'clock' matter in prostate cancer? Cancer Epidemiology, Biomarkers and Prevention 15 3-5. (doi:10.1158/1055-9965.EPI-05-0631)

Received in final form 12 September 2016

Accepted 19 September 2016

Accepted Preprint published online 22 September 2016
(C) 2016 Society for Endocrinology Printed in Great Britain
Published by Bioscientifica Ltd. 